\title{
Article \\ (Not) Doing the Right Things for the Wrong Reasons: An Investigation of Consumer Attitudes, Perceptions, and Willingness to Pay for Bio-Based Plastics
}

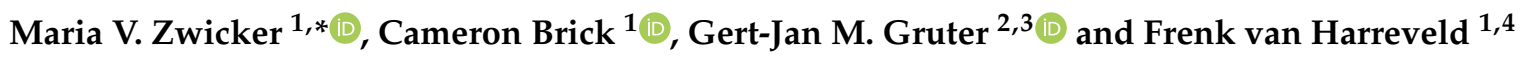 \\ 1 Department of Social Psychology, University of Amsterdam, Nieuwe Achtergracht 129-B, \\ 1018 WT Amsterdam, The Netherlands; c.brick@uva.nl (C.B.); F.vanHarreveld@uva.nl (F.v.H.) \\ 2 Industrial Sustainable Chemistry, University of Amsterdam, Science Park 904, \\ 1098 XH Amsterdam, The Netherlands; G.J.M.Gruter@uva.nl \\ 3 Avantium NV, Zekeringstraat 29, 1014 BV Amsterdam, The Netherlands \\ 4 National Institute for Public Health and the Environment (RIVM), Antonie van Leeuwenhoeklaan 9, \\ 3721 MA Bilthoven, The Netherlands \\ * Correspondence: m.zwicker@uva.nl; Tel.: +31-6-8724-9100
}

check for updates

Citation: Zwicker, M.V.; Brick, C.; Gruter, G.-J.M.; van Harreveld, F. (Not) Doing the Right Things for the Wrong Reasons: An Investigation of Consumer Attitudes, Perceptions, and Willingness to Pay for Bio-Based Plastics. Sustainability 2021, 13, 6819. https://doi.org/10.3390/su13126819

Academic Editors: Tomas Baležentis and Iris Vermeir

Received: 24 March 2021

Accepted: 7 June 2021

Published: 16 June 2021

Publisher's Note: MDPI stays neutral with regard to jurisdictional claims in published maps and institutional affiliations.

Copyright: (c) 2021 by the authors. Licensee MDPI, Basel, Switzerland. This article is an open access article distributed under the terms and conditions of the Creative Commons Attribution (CC BY) license (https:// creativecommons.org/licenses/by/ $4.0 /)$.

\begin{abstract}
Fossil-based plastics are significant contributors to global warming through $\mathrm{CO}_{2}$ emissions. For more sustainable alternatives to be successful, it is important to ensure that consumers become aware of the benefits of innovations such as bio-based plastics, in order to create demand and a willingness to initially pay more. Given that consumer attitudes and (inaccurate) beliefs can influence the uptake of such new technologies, we investigated participants' attitudes towards fossil-based and bio-based plastic, their perceived importance of recycling both types of plastic, their willingness to pay, and their perceptions of bio-based plastic in four studies (total $N=961$ ). The pre-registered fourth study experimentally manipulated information about bio-based plastic and measured willingness to pay for different types of plastic. The results suggest participants hold very favourable attitudes and are willing to pay more for bio-based products. However, they also harbour misconceptions, especially overestimating bio-based plastic's biodegradability, and they find it less important to recycle bio-based than fossil-based plastic. Study 4 provided evidence that educating consumers about the properties of bio-based plastic can dispel misconceptions and retain a favourable attitude and a high willingness to pay. We found mixed evidence for the effect of attitudes on willingness to pay, suggesting other psychological factors may also play a role. We discuss how attitudes and misconceptions affect the uptake of new sustainable technologies such as bio-based plastics and consumers' willingness to purchase them.
\end{abstract}

Keywords: plastic; bio-based plastic; willingness to pay; attitudes; recycling

\section{Introduction}

Plastics are an extensive family of different materials designed for specific applications. In our daily lives, we are continuously surrounded by plastic in grocery packaging, clothes, other fabrics, transportation, medical devices, household objects, and tools, including electronics. In 2019, global plastics production reached 370 million tonnes, with $39.6 \%$ for packaging [1]. While plastics are a valuable resource that benefit society in numerous ways, they also contribute to marine litter and climate change (emitting almost 1 billion metric tons of $\mathrm{CO}_{2}$ emissions in 2019) [2].

Consumers are becoming increasingly aware that plastic can have harmful effects on the environment, which is at least partially due to the increased media coverage on the topic over the past few years [3]. However, much of consumers' concern focuses on the post-consumption or end-of-life effects of plastic on the environment, such as recyclability, biodegradability, and reusability [4,5]. The effect of plastic on the environment, however, starts well before it hits store shelves-it starts with the extraction of fossil fuels. Around 
$99 \%$ of virgin plastics are derived from fossil fuels (i.e., oil, coal, or natural gas) [6]. This currently makes up about $6 \%$ of global oil consumption and by 2050 , it is expected that $20 \%$ of the current volume of global oil will be used for the production of plastic alone [7]. Consumers' focus on the end-of-life attributes of plastic makes sense as this stage in plastics' lifecycle is most visible to consumers and relevant to their own behaviour as they decide how to dispose of the product [5].

In the next 30 years, plastic volumes are expected to triple [8] or even quintuple to 1800 million tonnes per year [9], and $\mathrm{CO}_{2}$ emissions from plastic production will rise to 3-5 billion metric tonnes. In 2019, global anthropogenic $\mathrm{CO}_{2}$ was 38 billion tonnes [10] and the Paris agreement targets an $80-90 \%$ global reduction by 2050. For plastics to not overwhelm the total $2050 \mathrm{CO}_{2}$ emissions budget (4-8 billion tons), there are 30 years to reduce the carbon footprint of plastics. The only alternative carbon feedstock for making virgin (non-recycled) plastics is biomass [11].

Transitioning away from fossil-based plastics is difficult, especially because the continued increase in plastic production and use [1,12] suggests that proximity to plastic waste in itself is not enough to persuade consumers to change their behaviour. Technological developments alone are also not sufficient to successfully make the transition; the adoption of new technologies by consumers, as well as a change in attitude and behaviour, is key. In order for new, more sustainable plastic alternatives to be adopted, a different type of awareness is needed-not just of the pollution of natural environments, but also of the production process, carbon footprint, and specific characteristics of plastic products.

The overall aim of the current research is to investigate consumers' willingness to adopt and pay for alternatives to fossil-based plastic. We focus on bio-based plastics, which are plastics derived from renewable materials, or 'biomass' $[1,13,14]$, because biomass is the only alternative material for making virgin (non-recycled) plastics [11]. While product adoption and willingness to pay are important from an economic perspective, we also investigate the underlying psychological processes that make consumers more willing to pay. We therefore investigated several psychological factors that might influence consumers willingness to pay, such as attitudes and bio-based plastic perceptions (e.g., its recyclability and biodegradability). We also experimentally manipulated the knowledge participants received about bio-based plastics to determine how that affects their attitudes, willingness to pay, and perceived importance to recycle.

\subsection{Bio-Based Plastic}

With new technological advances such as bio-based plastics, it is possible to retain the advantages and characteristics of conventional fossil-based plastics while reducing the impact plastic has on global warming. Bio-based plastics are derived from 'biomass', such as sugar cane, starch, vegetable oils, etc. $[1,13,14]$. Regardless of being fossil- or bio-based, certain plastics are biodegradable (i.e., under very specific conditions, they can biodegrade into mainly $\mathrm{CO}_{2}$ and water, and compost), while others are not, depending on the application they were designed for $[1,13]$. Thus, many plastics made from biomass are not (readily) biodegradable (the bio-based plastics studied in this research are not) and therefore do not alleviate the pollution of natural environments. What makes bio-based plastics more sustainable than conventional fossil-based plastics is that they are produced from carbon that is already above the ground. Thus, even if bio-based plastics release the same amount of $\mathrm{CO}_{2}$ upon incineration as waste at the end of life as fossil-based plastics, the $\mathrm{CO}_{2}$ released was already above ground and no extra $\mathrm{CO}_{2}$ is added when using this $\mathrm{CO}_{2}$-biomass-bio-based plastic- $\mathrm{CO}_{2}$ cycle. The largest benefit of bio-based plastic therefore lies in the material that it is made of (i.e., superterranean renewable material of biological origin). One example of a new type of bio-based plastic is Polyethylene Furanoate or PEF, which is expected to reach consumers in the next few years. PEF, for instance, has a carbon footprint that is less than half of that of conventional plastic (43-56\% reduction in $\mathrm{CO}_{2}$ emissions $\left.[15,16]\right)$. 


\section{Lack of Knowledge}

For alternatives to conventional plastics to be successful, adoption by consumers is key to generate a market pull. Products made from bio-based plastic are initially more expensive, while production is small and the processes are not optimised. It is therefore essential for companies and governments to stimulate consumer demand, for example through marketing. Without consumer demand, there is no incentive for companies to adopt bio-based plastics, as this can be financially costly. It is therefore important to ensure that consumers become aware of the benefits of innovations such as bio-based plastics in order to create a demand for them. The present research therefore aims to investigate consumers' attitudes and perceptions towards bio-based plastics, as well as their willingness to pay a price premium. We also aimed to determine the effects that different levels of information about bio-based plastic can have on the above-mentioned variables.

While more and more plastic alternatives such as bio-based plastics are entering the market, consumers lack the knowledge of what it means if a product is 'bio-based' or 'biodegradable' [17]. While consumers report preferring more sustainable plastics over conventional ones, there seems to be a general lack of knowledge about the characteristics of bio-based products [5,17-20], giving rise to various misconceptions [21]. This might partially be due to the aforementioned tendency to focus on the end-of-life attributes of plastics, which creates a disadvantage for bio-based products, whose pro-environmental effects are based on their origin from renewable resources [5]. Another reason for this lack of knowledge about bio-based plastics is their rarity and the confusion created through the term 'bioplastics' which can refer to either the bio-based origin or the biodegradable character of a plastic [13]. Additionally, it can be difficult to differentiate between conventional and bio-based plastic products, since they are similar in appearance and attributes [14]. Whatever the cause, many consumers appear to think that bio-based products are automatically biodegradable, which is not necessarily the case. The lack of knowledge can lead consumers to form their attitudes based on incorrect associations and expectations about bio-based plastics [22]. What kind of expectations and attitudes consumers have towards bio-based plastic can influence their behaviour.

\subsection{Attitudes}

Attitudes are a key predictor of behaviour (for an extensive overview, see [23]). In the present research, we therefore investigate people's attitudes towards plastic (both bio-based and conventional) as a first step in understanding how to best persuade people to adopt a more sustainable plastic-behaviour. Some research suggests that attitudes towards bio-based plastics are one of the strongest influencers of purchase intentions for bio-based plastic products [14]; however, research on attitudes towards plastic, and especially bio-based plastic, is scarce. Some studies suggest that, while people report having general reservations about fossil-based plastics, they indicate having a favourable view of products made from renewable resources [5]. Other studies indicate that most people seem to have positive associations with 'bioplastics' (whether or not biodegradable) and bio-based technologies $[19,20,22]$. However, there are also studies that suggest that new environmental innovations, such as bio-based plastics, can evoke negative emotions, unfavourable attitudes, and lower purchase intentions (see [24]). Bio-based products can also produce simultaneously positive (related to environmental topics) and negative (related to technological topics) evaluations, generally causing uncertainty and mixed feelings [25]. We argue that consumers' positive and negative evaluations regarding plastic are likely to vary independently. The extent to which one thinks plastic is useful might very well be unrelated to how much one thinks plastic contributes to climate change [25]. In the present research, we therefore separately assess both the positive and negative evaluations people hold towards fossil-based and bio-based plastic, rather than in a single bipolar scale (for a similar approach, see [26]).

In some cases, consumers might have positive associations with bio-based plastics for the wrong reasons, i.e., most consumers think that all bio-based plastics are biodegradable. 
People's perceptions of bio-based plastics may become less positive when they realise that bio-based and biodegradable are completely disconnected features. Conversely, few consumers realise that plastics and climate change are connected, as discussed above, and that bio-based alternatives can be a solution to this problem. In this work, we continue the investigation into attitudes towards bio-based plastics by Zwicker et al. [26].-we assess people's attitudes towards both conventional and bio-based plastic in a series of four studies, to obtain a better understanding of people's general evaluation of these different types of plastics. We also report on how consumers' attitudes change (in a negative or in a positive way) after communicating factual information about biodegradability and carbon footprint of bio-based plastics (Study 4). Having a favourable attitude and accurate knowledge of bio-based plastic is the foundation of consumer acceptance and willingness to pay (more) for bio-based plastic. This shift will support a durable transition towards a more sustainable plastic economy.

\subsection{Overview of Studies}

In four online studies, we examined consumers' attitudes and perceptions about conventional and bio-based plastics. In our first study $(N=97)$, we aimed to investigate whether participants' attitudes differed with regard to conventional and bio-based plastics. Study $2(N=52)$ replicated these results and examined behavioural factors such as willingness to pay and perceived importance to recycle, in order to test the attitude-behaviour relationship. The third study $(N=508)$ aimed to replicate the results of the previous studies with a larger sample. It also assessed participants' most common misconceptions towards bio-based plastic, as they might influence both plastic-related attitudes and behaviour. To extend the correlational previous studies, Study $4(N=304)$ was a pre-registered experimental study that manipulated knowledge about bio-based plastic and measured the effect of this manipulation on attitudes, importance to recycle, willingness to pay, and objective pro-environmental behaviour. For an overview of the studies and measures, see Table 1. Additional analyses and more detailed information about the studies can be found in the Supplementary Materials (https://osf.io/p3ftu/).

Table 1. Overview of Studies 1 to 4 and the concepts they assessed.

\begin{tabular}{lcccc}
\hline \multicolumn{1}{c}{ Concepts Assessed } & $\begin{array}{c}\text { Study 1 } \\
(\boldsymbol{N = 9 7 )}\end{array}$ & $\begin{array}{c}\text { Study 2 } \\
(\boldsymbol{N}=\mathbf{5 2})\end{array}$ & $\begin{array}{c}\text { Study 3 } \\
(\mathbf{N}=\mathbf{5 0 8 )}\end{array}$ & $\begin{array}{c}\text { Study 4 } \\
(\mathbf{N}=\mathbf{3 0 4})\end{array}$ \\
\hline Attitudes & $\checkmark$ & $\checkmark$ & $\checkmark$ & $\checkmark$ \\
Perceived importance to recycle & & $\checkmark$ & $\checkmark$ & $\checkmark$ \\
Willingness to pay & & $\checkmark$ & $\checkmark$ & $\checkmark$ \\
Perceptions of bio-based plastic & & & $\checkmark$ & $\checkmark$ \\
Manipulation of level of knowledge & & & & $\checkmark$ \\
Prior knowledge & & & $\checkmark$ \\
\hline
\end{tabular}

All studies were approved by the Ethics Review Board of the Faculty of Social and Behavioural Sciences, University of Amsterdam, the Netherlands, designed using Qualtrics and distributed to participants from Western countries via the online crowdsourcing platform Prolific [27]. All data, study items, analysis scripts, and additional information are available at the Open Science Framework (https://osf.io/p3ftu). All analyses were conducted using SPSS version 24 and all power analyses were conducted using the R 'pwr' package [28].

\section{Study 1}

This exploratory study aimed to establish whether participants had differing attitudes towards fossil-based and bio-based plastic, and if this was the case, how they differed. We had no directional hypotheses before conducting this study. 


\subsection{Materials and Method}

\subsubsection{Participants and Procedure}

See Table 2 for sample details of the 97 participants. After consenting to take part, participants reported their demographic information and responded to a series of qualitative questions concerning conventional and bio-based plastic that are outside the scope of this manuscript. They then reported their attitudes towards both types of plastic before being debriefed and paid.

Table 2. Sample details for Studies 1 to 4.

\begin{tabular}{|c|c|c|c|c|}
\hline & Study 1 & Study 2 & Study 3 & Study 4 \\
\hline$N$ & 97 & 52 & 508 & 304 \\
\hline \multicolumn{5}{|l|}{ Gender } \\
\hline Female (\%) & $61(62.9 \%)$ & $29(55.8 \%)$ & $268(52.8 \%)$ & $164(53.9 \%)$ \\
\hline Male (\%) & $36(37.1 \%)$ & $23(44.2 \%)$ & $232(45.7 \%)$ & $137(45.1 \%)$ \\
\hline Preferred not to say/other (\%) & $0(0 \%)$ & $0(0 \%)$ & $8(1.6 \%)$ & $3(1.0 \%)$ \\
\hline Mean age (SD) & $33.9(12.1)$ & $28.5(9.7)$ & $32.4(10.8)$ & $34.7(12.1)$ \\
\hline Age range & $18-64$ years & 18-68 years & $18-72$ years & $18-74$ years \\
\hline \multicolumn{5}{|l|}{ Education completed (\%) } \\
\hline secondary education & $30.9 \%$ & $26.9 \%$ & $24.2 \%$ & $26.9 \%$ \\
\hline undergraduate degree & $50.5 \%$ & $42.3 \%$ & $47.4 \%$ & $42.3 \%$ \\
\hline postgraduate education & $8.4 \%$ & $21.2 \%$ & $17.9 \%$ & $21.2 \%$ \\
\hline trade/technical/or vocational training & $9.3 \%$ & $9.6 \%$ & $8.7 \%$ & $9.6 \%$ \\
\hline primary school & $1.0 \%$ & $0.0 \%$ & $1.8 \%$ & $0.0 \%$ \\
\hline \multicolumn{5}{|l|}{ Country of residence } \\
\hline United Kingdom & $58 \%$ & $46 \%$ & $33.1 \%$ & $61.5 \%$ \\
\hline Europe & $28 \%$ & $44 \%$ & $46.1 \%$ & $29.6 \%$ \\
\hline North America & $14 \%$ & $8 \%$ & $17.1 \%$ & $4.3 \%$ \\
\hline Other & $0 \%$ & $2 \%$ & $3.7 \%$ & $4.6 \%$ \\
\hline
\end{tabular}

\subsubsection{Attitudes}

In all four studies, we assessed participants' attitude towards both conventional and bio-based plastic. Individuals can hold both positive and negative attitudes about a target [29], leading to ambivalence and mixed feelings [30]. We therefore adapted the split semantic differential scale proposed by Kaplan [31] and later used by Itzchakov and Van Harreveld [32]. Zwicker and Nohlen [26] adapted the scale for the use on conventional and bio-based plastic, the same version of the scale used in the present research. We measured participants' attitudes towards (bio-based) plastic by asking them to consider only the positive/negative aspects of using (bio-based) plastic products and enquiring how (un)favourable their evaluation of (bio-based) plastic use is on a seven-point Likert scale ranging from $1=$ Not at all (un)favourable to $7=$ Extremely (un)favourable (in Study 1 , a five-point version of the same scale was used).

\subsection{Results}

We conducted a series of paired samples t-tests to compare people's attitudes towards conventional plastic with their attitudes towards bio-based plastics. A sensitivity analysis revealed $80 \%$ power to detect a medium effect size $(d=0.41)$ at $\alpha=0.05$. As illustrated in Figure 1 (Study 1), evaluations of conventional plastic were less positive than those of biobased plastic, $t(96)=-5.76, p<0.001, d=-0.59$. Participants were also more unfavourable 
towards conventional than towards bio-based plastic, $t(96)=7.17, p<0.001, d=0.73$. This indicates that participants had both more positive and less negative attitudes towards bio-based plastics than towards conventional plastics. While there was no difference between positive and negative attitudes towards conventional plastic $t(96)=-1.43, p=0.16$, $d=-0.15$, participants reported being more positive than negative towards bio-based plastic, $t(96)=-10.71, p<0.001, d=1.09$.

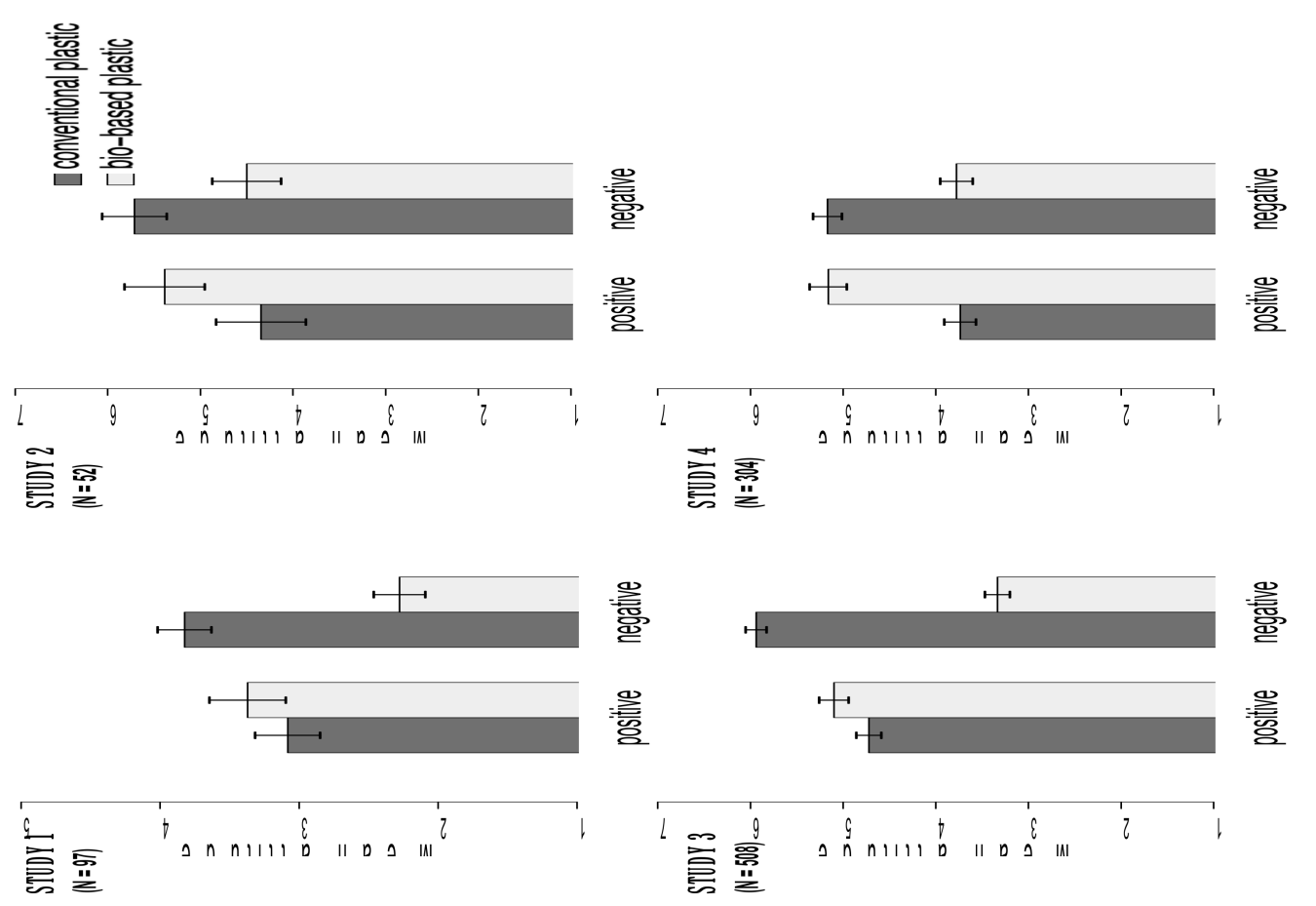

Figure 1. Mean attitudes towards regular and bio-based plastic for Studies 1 to 4 . Error bars represent the standard error.

\subsection{Discussion}

Study 1 provided a first indication that participants' attitudes differ from one type of plastic to another. The results show that bio-based plastic was evaluated more positively (and less negatively) than conventional plastic. We next aimed to replicate this finding and assess behavioural factors related to bio-based plastic, namely the perceived importance to recycle the different types of plastic and people's willingness to pay.

\section{Study 2}

The first study indicated positive attitudes towards bio-based products. As attitudes are presumed to influence behaviour, we wanted to investigate whether attitudes would relate to participants' willingness to pay more for bio-based products. Due to small production scales and an early stage of technology development, these new materials are likely to be initially more expensive. For new and more sustainable technologies to be made widely available, companies need to know that consumers are willing to pay more to make the financial investment worth it. There are studies that suggest consumers would indeed be willing to pay 'a little' more for bio-based products [19], but the literature is sparse on the willingness to pay for bio-based products. We hypothesised that consumers would have a more positive (and less negative) attitude towards bio-based plastic than towards fossilbased plastic (i.e., replicating the results found in Study 1). Whether participants would be willing to pay more for a bio-based product than for an item made from conventional plastic was purely exploratory. We did expect that attitudes would influence participants' willingness to pay, although we had no clear predictions about whether it would be positive 
attitudes towards bio-based or negative ones about fossil-based plastic (or both) that would drive willingness to pay.

Furthermore, despite the generally positive attitudes towards bio-based plastic, uncertainty remains about how to correctly dispose of bio-based products $[19,33]$. People may know how to correctly dispose of non-biodegradable recyclable plastic but not how to deal with (biodegradable) bio-based plastic [33]. This is problematic because the common misconception that all bio-based plastics are biodegradable could lead to a continuation (or even increase) of littering, with consumers assuming that this type of plastic waste will degrade in nature. Additionally, bio-based plastic might be perceived as a technical solution to the plastic problem that does not require specific actions or a change in behaviour from the individual, effectively removing any responsibility from the consumer to dispose of plastic products properly [34]. We therefore also assessed how important participants considered recycling of both conventional and bio-based plastics. This was purely exploratory and we did not have a pre-formulated hypothesis about whether there would be a difference in perceived importance to recycle.

\subsection{Materials and Method}

\subsubsection{Participants and Procedure}

See Table 2 for sample details of the 52 participants. After consenting to take part, participants received information about conventional and bio-based plastics. They then reported their willingness to pay, their perceived importance to recycle, and their attitudes about both types of plastic. Before being debriefed and paid, they also filled in their demographic information.

\subsubsection{Willingness to Pay}

Studies 2, 3, and 4 included a measure of participants' willingness to pay. This measure was designed by Zwicker and Nohlen [26] and was chosen for its simplicity and face validity. Participants were shown an image of a $1.5 \mathrm{~L}$ water bottle made from conventional plastic and told that it costs 1 EUR. They were then asked how much they would be willing to pay for the same bottle if it were made from bio-based plastic instead. Participants responded on a continuous slider measure reaching from 0-2 EUR, with the slider's starting position being 1 EUR.

\subsubsection{Importance to Recycle}

Importance to recycle was assessed by two items (one for each type of plastic) asking participants how important they thought it was to recycle items made from conventional and bio-based plastic on a seven-point Likert scale ranging from $1=$ not at all important to $7=$ extremely important. The items did not significantly correlate, $r(50)=0.26, p=0.063$, and were treated separately in the analysis. This measure was again chosen for its face validity and to get a first indication of possible differences in recycling perception between the different plastic types.

\subsection{Results}

\subsubsection{Attitudes}

Paired samples $t$-tests compared participants' attitudes towards conventional and bio-based plastic. The means and standard errors are displayed in Figure 1 (Study 2). As hypothesised, participants felt more positive towards bio-based than towards conventional plastic $t(51)=-5.70, p<0.001, d=-0.79$. Conversely, participants reported being more negative towards regular plastic than towards bio-based plastic, $t(51)=2.76, p=0.008$, $d=0.38$. This replicates the findings from Study 1 and indicates that participants again had both more positive and less negative attitudes towards bio-based plastics than towards regular plastics. Unlike in Study 1, participants felt significantly more negative than positive towards conventional plastic, $t(51)=-3.04, p=0.004, d=-0.42$. As in the 
first study, their general attitudes were more positive than negative concerning bio-based plastics, $t(51)=5.68, p<0.001, d=0.79$.

\subsubsection{Importance to Recycle}

Participants found it important to recycle in general. The distributions for participants' perceived importance to recycle were significantly skewed ( -3.45 and -2.18 for conventional and bio-based plastic, respectively, $S E=0.33$ ). We therefore conducted a Wilcoxon signed-rank test, which suggested that participants found it more important to recycle items made from conventional plastic $(M=6.8, S D=0.7)$ than bio-based plastic $(M=6.4$, $S D=1.1$ ), $T=20, p=0.021, r=-0.33$; see Figure 2 (Study 2).

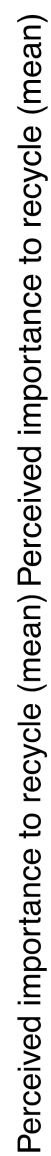

\section{STUDY 2}

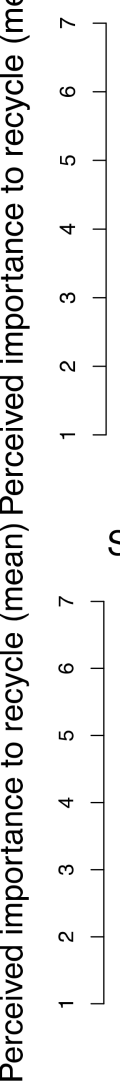

STUDY 4

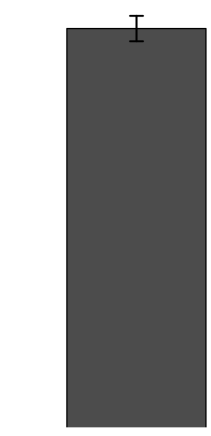

Conventional plastic

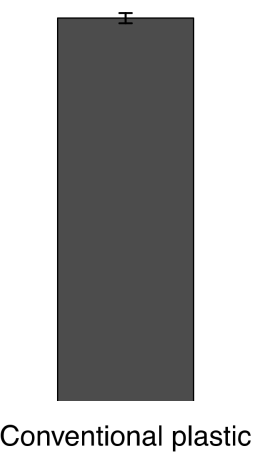

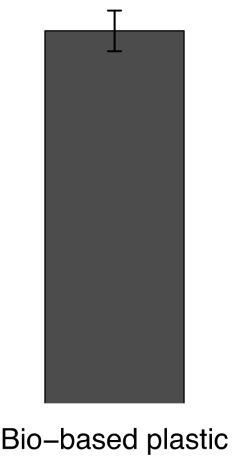

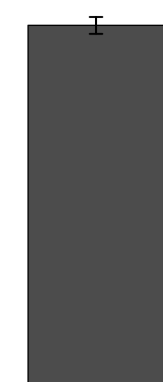

Bio-based plastic

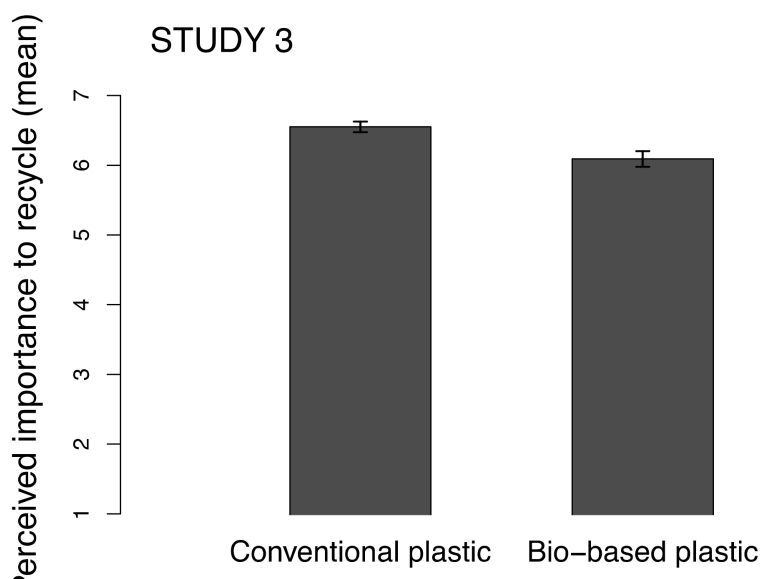

Conventional plastic Bio-based plastic

Figure 2. Mean perceived importance to recycle for regular and bio-based plastic for Studies 2, 3 and 4 . Error bars represent the standard error.

\subsubsection{Willingness to Pay}

A paired samples $t$-test showed that participants were willing to pay more for a biobased than a conventional plastic bottle, $t(51)=-6.18, p<0.001, d=0.86$, with the majority of participants having this preference $(70.6 \%)$. On average, participants reported that they would be willing to pay EUR 1.30 (median $=1.20, S D=0.36$ ) for a bio-based bottle, $30 \%$ more than for a water bottle made from conventional plastic that costs EUR 1.

We also ran a bootstrapped regression (5000 bootstraps) to determine the relationship between people's attitudes and willingness to pay. The results suggest that, while attitude towards conventional plastic predicted willingness to pay for a bio-based plastic product, $B=-0.041, t(49)=-2.04, p=0.047,95 \% \mathrm{CI}_{\text {Bootstrap }}[-0.081,-0.001]$, attitude towards bio-based plastic did not, $B=0.031, t(49)=0.96, p=0.34,95 \% \mathrm{CI}_{\text {Bootstrap }}[-0.043,0.095]$. Together, the attitudes towards both types of plastic did not significantly explain the 
variance of people's reported willingness to pay for the bio-based product $\left(R^{2}=0.088\right.$, $F(2,49)=2.37, p=0.104)$.

\subsection{Discussion}

Study 2 replicated that participants have more positive attitudes toward bio-based than conventional plastic and that this was driven by being more positive and less negative about the more sustainable plastic. Study 2 also demonstrated that people report being willing to pay more for a bio-based plastic water bottle. The results suggest that participants' attitudes towards conventional but not bio-based plastic might have influenced their willingness to pay more for a bio-based product. This contradicts findings by Klein and EmbergerKlein [14] and might relate to the fact that consumers are willing to pay more when feeling guilty about their use of conventional plastic [26]. This would suggest willingness to pay to be mainly driven by an aversion to conventional plastic, rather than liking of bio-based plastic. Participants also reported finding it less important to recycle bio-based plastic. This indicates that, while participants have positive attitudes towards bio-based plastic, they may also have misconceptions which may drive their apparent willingness to pay, as well as their perception that it is less important to recycle bio-based plastic. In practice, it is just as important to recycle bio-based plastic as regular plastic, as both are harmful to the environment as they degrade slowly. One limitation of this study was its low statistical power due to the small sample size. A sensitivity power analysis revealed $80 \%$ power to detect a medium effect of $d=0.57$ at $\alpha=0.05$ (paired samples $t$-test). We therefore aimed to replicate and extend the findings with a larger sample size.

\section{Study 3}

Previous research suggests that consumers lack knowledge about bio-based plastics and thus fill this knowledge gap with assumptions. That all bio-based plastics are biodegradable seems to be the most common misconception [5,17-19]; however, there is also uncertainty about the disposal $[19,33]$ and recyclability (Study 2 ) of bio-based products. Other perceptions pertaining to bio-based plastic are concerns about the production of biomass (required to make bio-based plastic) leading to deforestation and competition with land for food production $([19,22,26]$ Supplementary Materials, Study 1$)$. This is not true. Today, bio-based plastics are mostly made from carbohydrate-rich food crops, such as corn, sugar cane, and plant oil (i.e., first generation feedstock). However, land use for the production of bio-based plastic only accounts for $0.01 \%$ of agricultural land use, is predicted to stay this low, and is not in competition with land use for food or animal feed growth $[35,36]$. Research is also being carried out on large-scale use of second-generation feedstock (crops and plants not suitable for human or animal consumption, such as straw, forestry residues, corn stover, or bagasse, which are usually left on the field) and third generation feedstock (i.e., biomass derived from algae) [35,37].

As these kinds of perceptions might influence consumers' (bio-based) plastic-related attitudes, behaviour, and willingness to pay, we investigated next whether participants shared these perceptions. As in the previous study, we also assessed participants' general attitudes about both conventional and bio-based plastic, their perceived importance to recycle, and willingness to pay.

While we expected that our participants would share (at least some of) the perceptions of bio-based plastic found in previous research, we did not have any specific hypotheses as to the frequency of these perceptions. As in Study 2, we hypothesised that consumers would have a more positive (and less negative) attitude towards bio-based plastic than towards fossil-based plastic, and that attitudes would be related to willingness to pay. Again, we did not make any predictions about whether it would be attitudes towards bio-based or fossil-based plastic or both that would relate most strongly to willingness to pay (we found the sample size in Study 2 too small to add a specific direction towards our expectation based on its findings). We also hypothesised that participants would be willing to pay more for a bio-based than for a fossil-based plastic bottle and that they would find it 
more important to recycle products made from conventional plastic than those made from bio-based plastic (i.e., direct replication of Study 2's results).

\subsection{Materials and Method}

\subsubsection{Participants and Procedure}

See Table 2 for sample details. A sensitivity power analysis (paired samples $t$-test) revealed that with a sample of 508 participants we had $80 \%$ to detect a small effect $(d=0.18)$ at $\alpha=0.05$.

After reading the information letter and consenting to take part, participants read information about the difference between conventional and bio-based plastics (Supplementary Materials). First, participants reported their perceived importance to recycle and their attitudes about conventional, then about bio-based plastic. Next, they responded to the perception/misconception items. Finally, their demographic information was noted, and the participants were debriefed and paid.

\subsubsection{Perceptions of Bio-Based Plastic}

We assessed four common perceptions concerning plastic made from biomass pertaining to its recyclability, biodegradability, deforestation, and competition for land used for food production. Participants indicated how much they agreed with these four items on a seven-point Likert scale ranging from $1=$ strongly disagree to $7=$ strongly agree. These items were based on the results of mainly qualitative research (e.g., $[19,22,26])$, formulated as one-item measures, as there is very little quantitative research on the topic of bio-based plastic perceptions so far.

\subsection{Results}

\subsubsection{Attitudes}

A paired-sampled $t$-test comparing participants' attitudes towards conventional and bio-based plastic suggested that participants felt more favourable towards bio-based plastic than towards conventional plastic, $t(507)=-16.64, p<0.001, d=-0.74$ (means and SEs displayed in Figure 1, Study 3). Participants also felt more unfavourable towards regular plastic than towards bio-based plastic, $t(507)=17.80, p<0.001, d=0.79$. This replicates the findings from the previous two studies. As in Study 2, participants were more negative than positive towards regular plastic $(t(507)=-3.43, p<0.001, d=-0.15)$ and more positive than negative towards bio-based plastic $(t(507)=26.61, p<0.001, d=1.18)$. Our hypotheses concerning attitudes were therefore confirmed.

\subsubsection{Importance to Recycle}

Again, the general perceived importance to recycle was very high. Due to the skewed nature of the data $(-2.40$ and -1.52 for regular and bio-based plastic, respectively, $S E=0.11$ ), we conducted a Wilcoxon signed-rank test to determine whether there was a difference in how important participants found it to recycle the two different types of plastic. As in the previous study, participants found it more important to recycle items made from conventional plastic $(M=6.55, S D=0.86)$ than from bio-based plastic $(M=6.1$, $S D=1.3$ ) $, T=4120, p<0.001, r=-0.35$ (Figure 2, Study 3), supporting our hypothesis.

\subsubsection{Perceptions of Bio-Based Plastic}

As illustrated in Figure 3, most participants thought that bio-based plastic could be recycled (as is the case for the bio-based plastic studied here). However, participants also thought that bio-based plastic was biodegradable, which is not necessarily the case. Participants were not as concerned about the production of bio-based plastic resulting in deforestation, or competing with land otherwise used for food production. See Table 3 for response frequencies. 


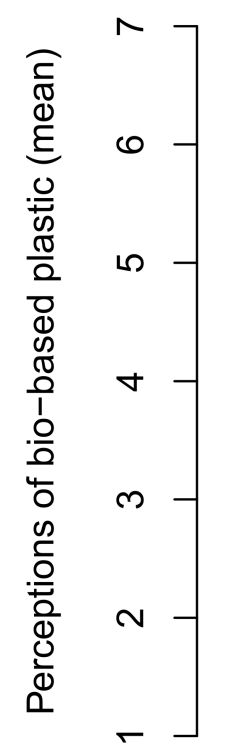

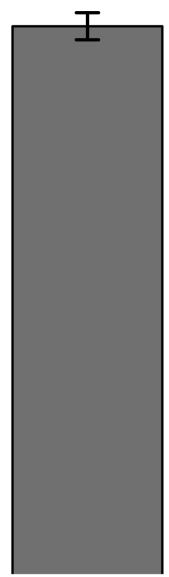

Recyclable

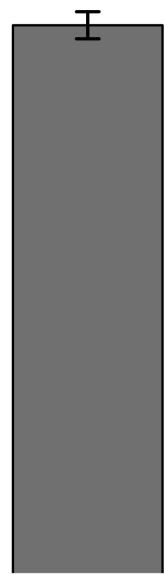

Biodegradable
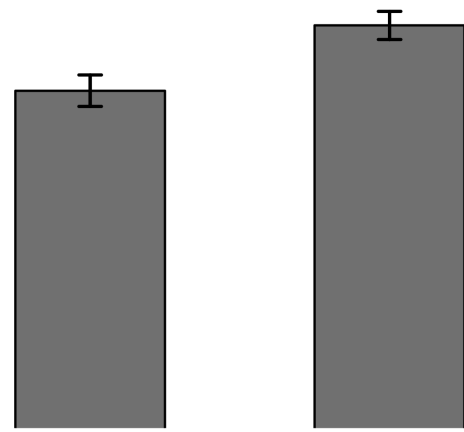

Deforestation Food competition

Figure 3. Common perceptions of bio-based plastic. Error bars represent the standard error (Study 3, $N=508$ ).

Table 3. Response frequencies to the perceptions of bio-based plastic (Study 3, $N=508$ ).

\begin{tabular}{|c|c|c|c|c|}
\hline & \multicolumn{4}{|c|}{ Response Frequency (\%) } \\
\hline & Recyclability & Biodegradability & Deforestation & Food Competition \\
\hline 1 Strongly disagree & $3(0.6 \%)$ & $4(0.8 \%)$ & $39(7.7 \%)$ & $19(3.7 \%)$ \\
\hline 2 & $6(1.2 \%)$ & $8(1.6 \%)$ & $58(11.4 \%)$ & $23(4.5 \%)$ \\
\hline 3 & $10(2 \%)$ & $7(1.4 \%)$ & $86(16.9 \%)$ & $40(7.9 \%)$ \\
\hline 4 Neither agree nor disagree & $96(18.9 \%)$ & $87(17.1 \%)$ & $172(33.9 \%)$ & $207(40.7 \%)$ \\
\hline 5 & $92(18.1 \%)$ & $100(19.7 \%)$ & $81(15.9 \%)$ & $121(23.8 \%)$ \\
\hline 6 & $144(28.3 \%)$ & $143(28.1 \%)$ & $50(9.8 \%)$ & $69(13.6 \%)$ \\
\hline 7 Strongly agree & $155(30.5 \%)$ & $154(30.3 \%)$ & $19(3.7 \%)$ & $27(5.3 \%)$ \\
\hline Total $N$ & $506(99.6 \%)$ & $503(99 \%)$ & $505(99.4 \%)$ & $506(99.6 \%)$ \\
\hline
\end{tabular}

\subsubsection{Willingness to Pay}

A large majority of participants $(78.6 \%)$ indicated that they would be willing to pay a price premium for a bio-based water bottle. On average, participants reported being willing to pay EUR 1.20 for the bio-based plastic bottle (median $=1.15, S D=0.3$ ). This suggests that they were willing to pay $20 \%$ more for a water bottle made from bio-based plastic than for one made from conventional plastic (which costs EUR 1), thereby supporting our hypothesis.

We also ran a bootstrapped regression (5000 bootstraps) to determine the relationship between participants' attitudes towards conventional and bio-based plastic and their selfreported willingness to pay. The results suggest that both attitude towards conventional plastic $\left(B=-0.012, t(505)=-2.49, p=0.013,95 \% \mathrm{CI}_{\text {Bootstrap }}[-0.022,-0.003]\right)$ and towards bio-based plastic $\left(B=0.018, t(505)=3.22, p=0.001,95 \% \mathrm{CI}_{\text {Bootstrap }}[0.007,0.029]\right)$ predict willingness to pay for a bio-based plastic product. Together, the attitudes towards both types of plastic explained 3\% of variance of people's reported willingness to pay, $R^{2}=0.029$, $F(1,505)=7.58, p<0.001$.

\subsection{Discussion}

In Study 3 we directly replicated that participants were both more positive and less negative towards bio-based compared to conventional plastic. We also found that the assumptions or misconceptions about bio-based plastic found in previous literature 
(i.e., concerning recyclability, biodegradability, deforestation, and competition with food production) were also present in the current sample, with the incorrect assumption that bio-based products are biodegradable being most prevalent. We also found a strong belief in the recyclability of bio-based plastic, but also replicated that participants found it less important to recycle bio-based compared to conventional plastic products. We again found that participants were willing to pay more for bio-based than fossil-based plastic products. While in Study 2 we only found attitudes towards conventional plastic to be predictive of willingness to pay, in Study 3 we found that attitudes towards both plastic types influenced willingness to pay for a bio-based bottle.

Studies 1-3 were exploratory and correlational, and assessed self-reported willingness to pay rather than objective behaviour. These limitations were addressed in the final study, which was experimental and pre-registered (https: / / aspredicted.org/blind.php?x=5bw9yz).

\section{Study 4}

Above, participants evaluated bio-based plastic more favourably and reported being willing to pay more for it than for conventional plastic, with some indication of attitudes being related to willingness to pay. Having only assessed self-reported willingness to pay in our previous studies, we also assessed objective behaviour in the form of a donation. We added a measure of objective behaviour because of the well-known inconsistency or 'gap' between what consumers say they are going or willing to do and what they actually do. Research suggests that models that predict behaviour solely based on intentions, are wrong up to $90 \%$ of the time (see [38]).

Study 3 suggested that many participants had misconceptions, especially about the biodegradability of bio-based plastic. It is therefore unclear whether the positive attitudes and willingness to pay are (at least partially) due to their misconception of biodegradability and its consequences (e.g., less marine pollution). Such attitudes that are positive for the wrong reasons may lead to disillusionment among consumers who learn more about the nature of bio-based plastics. Indeed, some research suggests that when confronted with information that bio-based plastic either is not biodegradable, or only under very specific composting conditions (as is the case for biodegradable plastic), consumers can react 'shocked and disappointed' [22].

In the present study, we investigated ways through which such disillusionment may be avoided. We manipulated the amount of information about bio-based plastics participants received in order to vary misconceptions. The main question was whether people still feel positive towards and are willing to pay more for bio-based plastic after learning that not all bio-based plastic is biodegradable and that its true advantage is lowering $\mathrm{CO}_{2}$ emissions. We again focus on bio-based plastic that is not biodegradable. This allows us to distinguish between participants' attitudes towards bio-based plastic from their attitudes towards biodegradability [5].

\subsection{Conditions and Hypotheses}

We used three conditions (control, negative, balanced) in which we varied the amount of information about bio-based plastic participants received, with the aim to reduce misconceptions about biodegradability. In particular, we wanted to be able to distinguish between a partial (negative condition) and complete resolution (balanced condition) of misconceptions. While positive attitudes are better than negative ones for the adaptation of more sustainable plastics, positive attitudes based on misconceptions can prove fragile when people learn more about the actual properties of bio-based plastic. In addition, there are good reasons for consumers to be positive about bio-based plastics that are based on renewable resources and reduce $\mathrm{CO}_{2}$ emissions. While reducing the misconceptions might not lead to as positive of an attitude than the one many people hold before learning more about bio-based plastic, it may lead to more stable attitudes. 


\subsubsection{Control Condition}

The control condition was the baseline in which participants received the same information about bio-based plastic as in Studies 2 and 3-they read that bio-based plastic is entirely or partially made from biomass and is similar in appearance and function to conventional plastic. Here, we expected the same results as in the previous studies, namely that people feel positive about bio-based plastic. We also expected the majority of participants to believe that bio-based plastic is always biodegradable and we did not expect them to know much about the $\mathrm{CO}_{2}$ footprint of bio-based plastic (or regular plastic for that matter).

\subsubsection{Negative Condition}

In the negative condition, participants received the same information about biobased plastic as in the control condition plus information that bio-based plastic is not necessarily biodegradable. This condition aimed to remove any misconceptions about the biodegradability of plastic and the linked perceived advantage to marine pollution and wildlife participants might hold. We therefore expected people's attitude about biobased plastic to become less positive relative to the control condition, but expected their knowledge about biodegradability to increase.

\subsubsection{Balanced Condition}

The balanced condition provided the same information as the negative condition with an added description of what makes bio-based plastic more sustainable (i.e., a smaller $\mathrm{CO}_{2}$ footprint). In this condition, we hypothesised the attitude towards bio-based plastic to be less positive than in the control condition, but more positive than in the negative condition. Because participants in this condition have more knowledge about both the lack of biodegradability and the $\mathrm{CO}_{2}$ benefits of bio-based plastic, we expected their attitudes about bio-based plastic to be more balanced and stable. A summary of the conditions and the corresponding hypotheses can be found in Table 4 . We did not expect the manipulations to affect attitudes towards conventional plastic.

Table 4. Hypotheses on product knowledge (i.e., biodegradability and $\mathrm{CO}_{2}$ footprint) and attitudes about bio-based plastic per condition (Study $4, N=304$ ).

\begin{tabular}{ccccc}
\hline & & \multicolumn{3}{c}{ Message Condition } \\
\cline { 3 - 5 } & & Control & Negative & Balanced \\
\hline \multirow{2}{*}{ Knowledge } & $\begin{array}{c}\text { Biodegradability } \\
\mathrm{CO}_{2} \text { footprint }\end{array}$ & low & correct & correct \\
& & none & none & correct \\
\hline Attitude & & + & - & $+/-($ stable $)$ \\
\hline
\end{tabular}

\subsubsection{Willingness to Pay and Attitudes}

We expected that the manipulation of knowledge would have an effect on people's willingness to pay (both self-reported and objective behaviour). In particular, we expected that compared to the control condition, participants would be willing to pay the lowest amount in the negative condition, in which participants are told that not all bio-based plastics are biodegradable. We hypothesised that adding a description of the benefits of bio-based plastic in the balanced condition would lead people to be willing to pay more in this condition than in the negative condition, but less than in the control condition.

\subsubsection{Importance to Recycle}

We expected misconceptions about the biodegradability of bio-based plastic to lead people to believe that it is less important to recycle bio-based plastic compared to conventional plastic. We therefore hypothesised that participants in the control condition would find it less important to recycle bio-based products than in the other two conditions. We 
did not expect knowledge about conventional plastic's or bio-based plastic's $\mathrm{CO}_{2}$ footprint to affect perceived importance to recycle.

\subsubsection{Other Hypotheses}

We also expected to replicate the results of the previous studies. We therefore hypothesised that participants would have a more positive (and less negative) attitude towards bio-based plastic than towards fossil-based plastic, that they would be willing to pay more for bio-based products than conventional plastic products, and that they would find it more important to recycle conventional plastic items compared to bio-based ones.

\subsection{Materials and Methods}

\subsubsection{Procedure}

After consenting to take part, participants were randomly assigned to one of three conditions: control, negative, and balanced. They were then asked how much knowledge they had about bio-based plastic and read an informational text about bio-based plastic (content depended on condition). This was followed by the manipulation check and the same questions about their attitude as in the previous studies. Participants were also asked how important they thought it was to recycle regular and bio-based plastic, before they indicated their willingness to pay (bottle and donation). Participants then filled out demographic information and were debriefed and paid.

\subsubsection{Participants}

See Table 2 for sample details. A sensitivity power analysis suggested that the sample size of 304 provided $80 \%$ power to detect relatively small effects of $f=0.18(d=0.23)$ at $\alpha=0.05$. The participants received GBP 0.85 as compensation for this approximately ten-minute study. We also asked participants about their prior knowledge of bio-based plastic, to test whether the general lack of knowledge about bio-based plastics reported in previous research $[5,17-20]$ is reflected in participants' self-reported knowledge level. The majority of participants reported having little prior knowledge of bio-based plastic (see Figure 4).

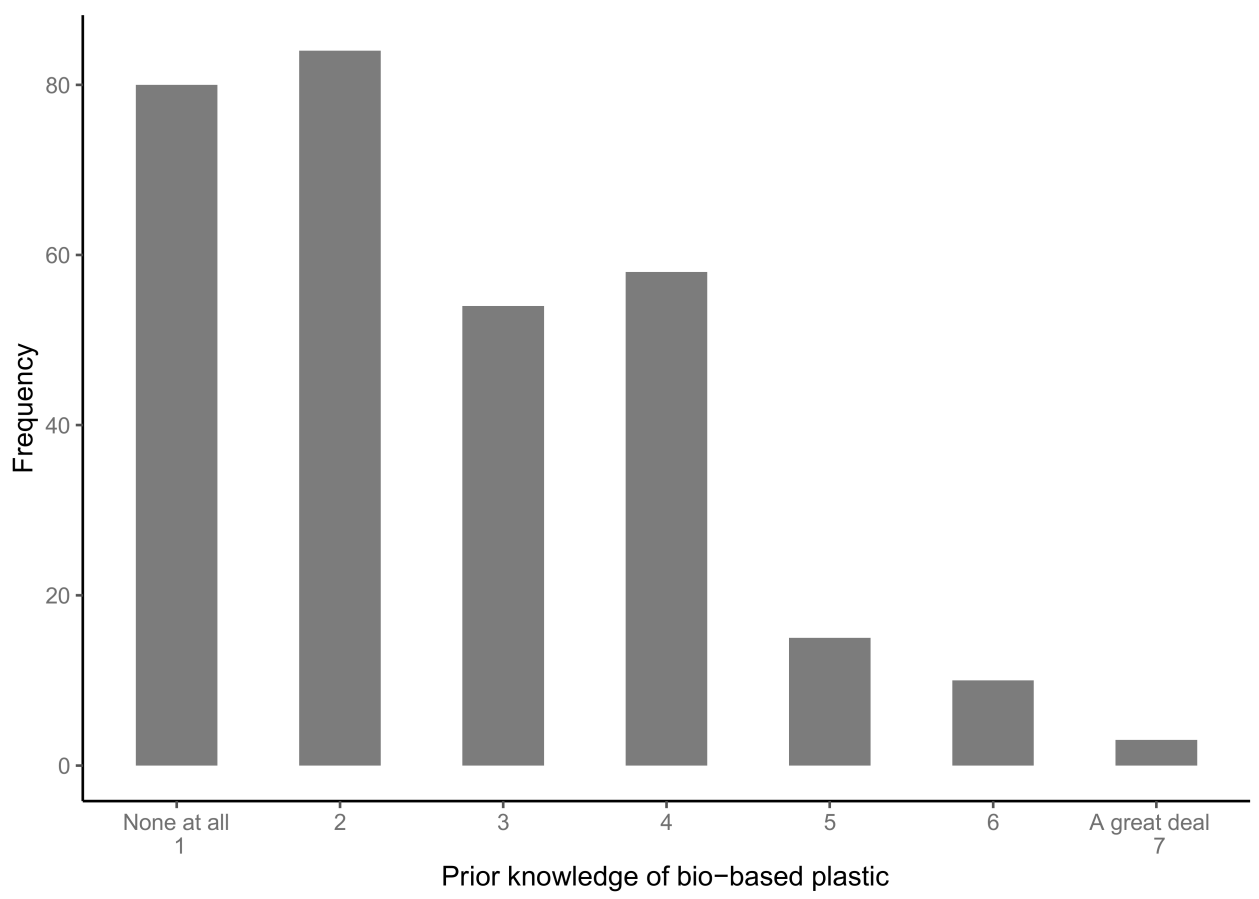

Figure 4. Frequencies of prior knowledge about bio-based plastic (Study $4, N=304$ ). 


\subsubsection{Manipulation}

In the different conditions (control, negative, balanced), participants read informational texts with varying amounts of information about bio-based plastic. They also completed a manipulation check that tested the knowledge about bio-based plastic they gained from reading the different manipulation texts. On a seven-point Likert scale $(1=$ completely untrue to $7=$ completely true $)$ they responded to two items each about the biodegradability of bio-based plastic (biodegradability score) and about the $\mathrm{CO}_{2}$ footprint of bio-based plastic $\left(\mathrm{CO}_{2}\right.$ score). Depending on condition, participants were expected to have different amounts of knowledge about bio-based plastic (see Table 4). The full text for each condition, as well as more information about the manipulation check, can be found in the Supplementary Materials.

\subsubsection{Willingness to Pay}

In addition to completing the self-reported bottle measure, participants were asked whether they would like to donate some (or all) of the earnings they receive for participating in this research to help plant real-life trees to reduce $\mathrm{CO}_{2}$, and if so, how much. Again, this was performed using a slider measure, this time reaching from 0 GBP ('I don't want to donate') to $0.85 \mathrm{GBP}$ (the amount they received for participating in the study).

\subsection{Results}

All analyses were pre-registered unless explicitly declared otherwise.

\subsubsection{Attitudes}

As in the previous studies, we ran a paired-sampled $t$-tests comparing participants' general attitudes (collapsed across all conditions) towards conventional and bio-based plastic (this analysis was not pre-registered). Participants felt much more favourable towards bio-based plastic than towards conventional plastic, $t(303)=-15, p<0.001$, $d=-0.86$ (for means and standard errors, see Figure 1, Study 4). Participants also felt more unfavourable towards conventional plastic than towards bio-based plastic, $t(303)=11.46$, $p<0.001, d=0.65$. This replicates Studies 1-3 and suggests that participants had both more positive and less negative attitudes towards bio-based plastics than towards conventional plastics. As in Studies 2 and 3, we found that participants were more negative than positive towards conventional plastic, $t(303)=-9.79, p<0.001, d=-0.56$, while having more positive than negative evaluations of bio-based plastic, $t(303)=10.05, p<0.001, d=0.58$.

\subsubsection{Manipulation Check}

We conducted two one-way ANOVAs to determine whether there was a main effect of condition on people's misconceptions (Figure 5a). As expected, there were differences between the conditions in misconceptions about bio-based plastics' biodegradability, $F(2,301)=124.56, p<0.001$. A Tukey post-hoc test further revealed that misconceptions were higher in the control condition than in the negative condition, $p<0.001$, $95 \% \mathrm{CI}[2.57,3.59]$, and the balanced condition, $p<0.001,95 \% \mathrm{CI}[2.23,3.21]$. There was no difference between the negative and balanced condition ( $p=0.19,95 \% \mathrm{CI}[-0.84,0.13])$. There was also a difference between conditions with regard to people's perceptions of bio-based plastic's $\mathrm{CO}_{2}$ impact, $F(2,301)=124.38, p<0.001$. A Tukey post-hoc test showed that this was driven by participants in the balanced condition having a much better understanding of bio-based plastic's $\mathrm{CO}_{2}$ advantage than participants in the control, $p<0.001$, $95 \% \mathrm{CI}[-2.61,-1.76]$, or negative conditions, $p<0.001,95 \% \mathrm{CI}[-3.08,-2.22]$. The difference between the control and negative condition was close to the alpha threshold ( $p=0.043$, $95 \%$ CI $[0.018,0.913])$. 
(a)
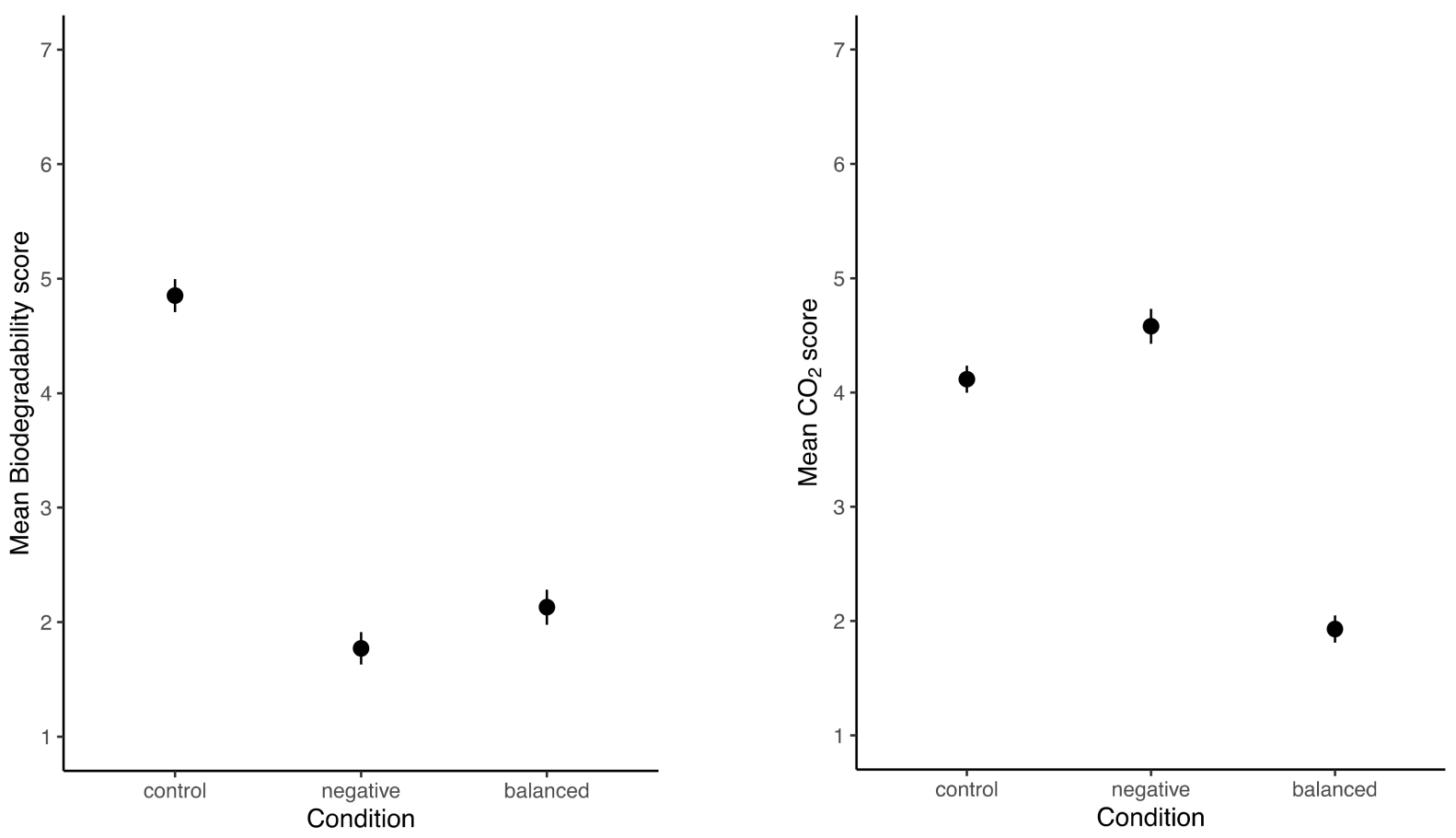

(b)

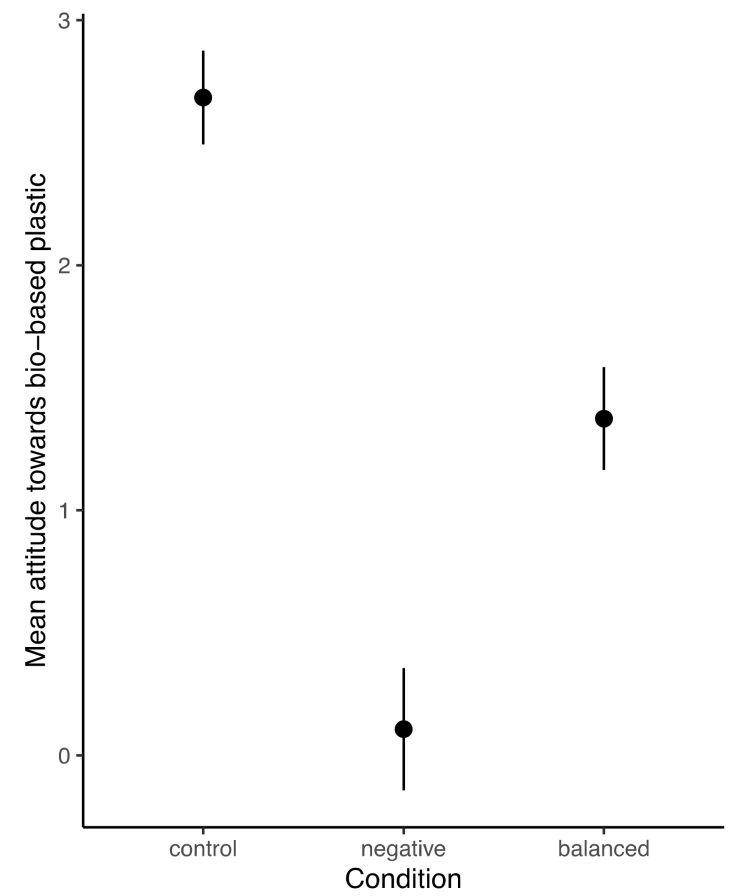

Figure 5. (a) Mean biodegradability and $\mathrm{CO}_{2}$ perception scores per condition (Manipulation Check, (Study $\left.4, N=304\right)$. Higher numbers indicate factual incorrectness or misconceptions. (b) Mean attitudes towards bio-based plastic per condition. The error bars represent the standard error. 


\subsubsection{Willingness to Pay and Attitudes}

Effect of Manipulation on Attitudes

To assess whether the (level of knowledge) manipulation affected people's attitudes towards bio-based (and conventional) plastic, two one-way ANOVAs were conducted with condition as the independent and product attitudes as the dependent variables. As expected, the manipulation had no effect on people's attitudes towards conventional plastic $(F(2,301)=1.44, p=0.238)$, but did significantly affect the attitudes people held towards bio-based plastic, $F(2,301)=32.59, p<0.001$.

A Tukey post-hoc test revealed that all conditions differed in attitudes towards biobased plastic (all $p$-values $<0.001$ ). As illustrated in Figure $5 b$, and as hypothesised, attitudes were most positive in the control condition and least positive in the negative condition, with the balanced condition in the middle.

Overall Willingness to Pay

The majority of participants (64.5\%) indicated that they were willing to pay more for a bio-based than a conventional plastic bottle. On average, participants reported that they were willing to pay $1.08 \mathrm{GBP}$ (median $=1.05, S D=0.28$ ) for the bio-based plastic bottle (less than in the previous studies). This suggests that they were willing to pay $8 \%$ more for a product made from bio-based plastic than for a bottle made from conventional plastic (which costs 1 GBP). With regard to objective behaviour, participants donated on average $0.20 \mathrm{GBP}$ (median $=0.05, S D=0.29$ ), which is $23.8 \%$ of the $0.85 \mathrm{GBP}$ they received. The majority of participants (57.6\%) were willing to act pro-environmentally by donating some amount of money. An exploratory bootstrapped (5000 bootstraps) two-tailed Pearson correlation between self-reported willingness to pay and objective donation behaviour revealed a small positive correlation, $r(302)=0.14,95 \%$ BCa CI [0.009, 0.27], $p=0.01$.

The Effect of Condition on Willingness to Pay

Table 5 shows the descriptions of participants' willingness to pay for both measures. We pre-registered several one-way ANOVAs to determine the effects of condition on the willingness to pay. However, because the data for both the bottle and donation measure were skewed, we conducted non-parametric tests instead.

Table 5. Willingness to pay descriptives per condition (Study $4, N=304$ ).

\begin{tabular}{ccccc}
\hline \multirow{3}{*}{ Bottle } & Condition & $\boldsymbol{N}$ & $\boldsymbol{M}$ (in GBP) & \multicolumn{1}{c}{$\boldsymbol{S D}$} \\
\hline \multirow{3}{*}{ Donation } & Control & 95 & 1.10 & 0.3 \\
\cline { 2 - 5 } & Negative & 94 & 1.05 & 0.3 \\
\cline { 2 - 5 } & Balanced & 115 & 1.10 & 0.3 \\
\cline { 2 - 5 } & Control & 95 & 0.20 & 0.3 \\
\cline { 2 - 5 } & Negative & 94 & 0.18 & 0.3 \\
\cline { 2 - 5 } & Balanced & 115 & 0.22 & 0.3 \\
\hline
\end{tabular}

With regard to the bottle measure, an independent samples Kruskal-Wallis test conducted due to the moderate skew (-0.83) of the self-reported willingness to pay data [39]. The results showed that willingness to pay for the bio-based plastic bottle was significantly affected by condition $H(2)=11.06, p=0.004$. Pairwise comparisons with adjusted $p$-values showed that participants in the negative condition were willing to pay 0.05 GBP less than in the control condition $(p=0.029, r=0.19)$, and in the balanced condition $(p=0.005$, $r=-0.22$ ). A one-sample Wilcoxon signed-rank test revealed that being willing to pay $1.05 \mathrm{GBP}$ for a bio-based plastic bottle constitutes a significant increase compared to the 1 GBP cost of a conventional plastic bottle, $T=20913, p<0.001, r=0.45$. There was no difference in willingness to pay between the control and the balanced condition $(p=1$, $r=-0.03)$. This suggests that when participants only received the additional information 
that bio-based plastic was not necessarily biodegradable, participants were less willing to pay. However, when they also read information about bio-based plastic's small $\mathrm{CO}_{2}$ footprint, participants were willing to pay as much as in the control condition.

The donation data were highly skewed (1.36) and thus an independent samples Kruskal-Wallis test was performed to determine the effects of condition on willingness to donate. The results suggest that condition did not affect donation behaviour, $H(2)=0.64$, $p=0.73$.

The Effect of Overall Attitude on Willingness to Pay

We ran a bootstrapped regression (5000 bootstraps) to determine the relationship between participant's attitudes towards conventional and bio-based plastic and their selfreported willingness to pay for the bio-based plastic bottle. Contrary to expectations and to the results of the previous study, neither attitudes towards conventional plastic $(B=-0.001$, $\left.t(301)=-0.13, p=0.900,95 \% \mathrm{CI}_{\text {Bootstrap }}[-0.015,0.014]\right)$ nor attitudes towards bio-based plastic $\left(B=0.009, t(301)=1.35, p=0.178,95 \% \mathrm{CI}_{\text {Bootstrap }}[-0.006,0.024]\right)$ predicted willingness to pay for a bio-based plastic product. The combined attitudes towards both types of plastic did not explain variance in reported willingness to pay, $R^{2}=0.01, F(2,301)=0.93$, $p=0.40$.

The same analysis was run for the donation measure with the same pattern of results. Neither attitude towards conventional plastic $(B=-0.009, t(301)=-1.36, p=0.174$, $\left.95 \% \mathrm{CI}_{\text {Bootstrap }}[-0.021,0.003]\right)$ nor towards bio-based plastic $(B=-0.004, t(301)=-0.58$, $\left.p=0.560,95 \% \mathrm{CI}_{\text {Bootstrap }}[-0.019,0.010]\right)$ predicted willingness to donate to a sustainable cause. Together, the attitudes towards both types of plastic did not explain variance in donation, $R^{2}=0.01, F(2,301)=1.36, p=0.26$.

\subsubsection{Importance to Recycle}

To test whether participants' misconceptions influence perceived importance to recycle, we performed several bootstrapped (5000 bootstraps) regressions. As predicted, knowledge of bio-based plastic's $\mathrm{CO}_{2}$ emissions did not influence participants' perceived importance of recycling bio-based plastic, $F(1,302)=0.38, p=0.54, B=-0.022,95 \%$ CI $[-0.09,0.048]$. However, the stronger participants' misconceptions about bio-based plastic's biodegradability, the less they thought recycling it was important, $F(1,302)=12.1, p<0.001, B=-0.108$, $95 \%$ CI $[-0.17,-0.041]$. When it comes to regular plastic, neither participants' knowledge about bio-based plastic's $\mathrm{CO}_{2}$ advantage, $F(1,302)=2.82, p=0.094, B=-0.037$, $95 \%$ CI $[-0.08,0.004]$ nor misconceptions about its biodegradability $F(1,302)=0.032$, $p=0.86, B=-0.003,95 \% \mathrm{CI}[-0.04,0.03]$ affected how important participants felt it was to recycle conventional plastic.

As in Studies 2 and 3, we also tested in an exploratory analysis whether there was a difference in how important participants found it to recycle both types of plastic (see Figure 2). Reported importance of recycling was overall very high. Because both the distributions were skewed (bio-based plastic: -1.78 , regular plastic: $-2.68, S E=0.14$ ), we performed a Wilcoxon rank-sum test. The results suggest that participants found it more important to recycle items made from conventional rather than bio-based plastic, $T=135, p<0.001, r=-0.43$. Given the results described above, this may be driven by those participants who harboured misconceptions about bio-based plastic's biodegradability.

\subsection{Discussion}

In this pre-registered experimental study, we replicated the findings from the previous three studies concerning participants' attitudes towards both conventional and bio-based plastic. We also successfully manipulated participants' level of knowledge about bio-based plastic and found that this influenced the attitudes they had towards bio-based plastic. In particular, participants' evaluations of bio-based plastics were most positive in the control condition (with misconceptions), least positive in the negative condition in which they were informed that not all bio-based plastics are biodegradable, and somewhere in between 
in the balanced condition in which participants received additional information about the small $\mathrm{CO}_{2}$ footprint of bio-based plastics.

As in Studies 2 and 3, participants reported being willing to pay more for a bio-based product, compared to one made from conventional plastic. However, the willingness to pay was lower than in the previous study, with participants indicating that they would be willing to pay on average 0.05 GBP more for a bio-based bottle. 0.05 GBP might not seem like much, but the production cost for a fossil-based plastic water bottle is between 0.0175 USD and 0.0375 USD [40]. Willingness to pay (only the bottle measure) was affected by condition, with participants in the negative condition being willing to pay less than in the other two conditions. Contrary to hypotheses, there was no effect of attitude on willingness to pay, nor did attitude influence the relationship between condition and willingness to pay. However, misconceptions about bio-based plastic's biodegradability led participants to think it less important to recycle products made from bio-based compared to those made from conventional plastic.

\section{General Discussion}

In combatting climate change, the development of more sustainable technologies has to go hand in hand with enhancing consumers' willingness to adopt these technologies. For example, consumer attitudes and perceptions are important when introducing a new technology such as bio-based plastic to the market, because cognitions can influence how much people are willing to pay for sustainable alternatives. There are many cases where more sustainable products or new technologies were not readily accepted by consumers, e.g., Nike's line of environmental 'Considered' shoes, car manufacturers switching their wiring from conventional to soy-based plastic, or attitudes towards genetic modification [25,41]. With the present research, we tested how this might be avoided for bio-based plastics.

The current results provide insight into consumers' attitudes towards conventional and bio-based plastics. Throughout all four studies, we found that participants had more positive and less negative evaluations of bio-based compared to conventional plastic products. Even when participants gained more knowledge about bio-based plastic and its characteristics, their attitudes remained positive (Study 4). However, attitudes alone do not paint the whole picture. We found some indication that attitudes about the different types of plastic directly affect people's willingness to pay (Studies 2 and 3). However, those results did not replicate in Study 4.

\subsection{Misconceptions}

That people have positive attitudes towards bio-based plastics is encouraging. However, throughout our studies, we also found that participants had very little prior knowledge about bio-based plastic and harboured several misconceptions, including that biobased plastic is by default biodegradable. This potentially makes these positive attitudes unstable, as they are likely based on these misconceptions. Positive attitudes that are based on misconceptions pose a risk for two reasons.

Firstly, learning that they have been positive for the wrong reasons may lead people to become more negative or even feel cheated because they had the wrong assumptions. Previous literature shows that consumers can react shocked and disappointed when told that bio-based plastic does not have all the properties they believed it to possess [22]. This was also demonstrated in the negative condition of Study 4-when participants were told that bio-based plastics are not by default biodegradable and thus do not alleviate problems such as marine pollution, their attitudes became more negative (see Figure $5 b$ ).

Secondly, people might attribute positive characteristics to bio-based plastic that are in fact untrue (that bio-based plastic is always biodegradable) and that can have unwanted behavioural consequences, such as littering. Throughout our research, we consistently found that participants perceived it less important to recycle products made from biobased plastic, compared to those made from conventional plastic. The results of our final 
study suggest that this is driven by those participants who believe that bio-based plastic is biodegradable.

As a result, we argue that it is important to educate people about the properties of different types of plastic and their uses, and render them as positive about bio-based plastics as they were before, but now in a more stable fashion, i.e., for the right reasons. Bio-based plastic can have many advantages such as being made from renewable biomass and having a smaller $\mathrm{CO}_{2}$ footprint. Some bio-based plastics, such as PEF, also possess similar or better chemical barrier qualities than conventional PET plastics. In our final study we also demonstrated that the information about bio-based plastic does not need to be extensive to successfully dispel misconceptions. In short, we believe that educating consumers about the properties of different types of plastic can lead to a more durable transition to sustainability than ignoring misconceptions about bio-based plastics. Our research indicates that consumers remain willing to pay a price premium and favourably evaluate this new, more sustainable technology.

From a psychological perceptive, it is valuable to investigate attitudes and perceptions of novel products, as they can determine whether or not the product will be adopted by consumers. Beliefs, both accurate and inaccurate, can drive consumers' willingness to pay and aid in predicting consumer behaviour. The present research thereby contributes to the existing literature by investigating both the applied and economic perspective of the novel bio-based plastics, while also studying the psychological factors (e.g., attitudes and perceptions) that influence consumers' willingness to pay. These results could therefore be useful not only for companies and their marketing campaigns, but also for policymakers trying to create a demand for more sustainable products. These insights also make it easier to study consumer perception and gauge willingness to pay for novel products.

\subsection{Willingness to Pay}

Previous research suggests that many consumers are willing to pay a premium for environmentally friendly products (see [16]). We found the same results with regard to bio-based products. Participants consistently reported being willing to pay 8-30\% more for a bio-based compared to conventional water bottle. Whether this willingness translates into objective behaviour is unknown; we only found a small correlation between participants self-reported willingness to pay and their objective donation behaviour in Study 4. This might be due to the differing nature of those two pro-environmental tasks (one assessing willingness to pay for a more sustainable plastic bottle and the other asking to donate actual money to help plant real-world trees), or due to a social desirability bias. However, it might also be due to the well-known intention behaviour gap [42], which describes the failure to translate intentions into action.

\subsection{Limitations and Future Directions}

While attitudes are essential for the acceptance of new technologies such as bio-based plastics, we found inconsistent evidence that attitudes influenced participants willingness to pay and no evidence that attitudes influenced objective behaviour. This suggests that non-attitude factors should also be investigated. For example, emotions might be a useful tool in encouraging pro-environmental behaviour [26,43]. Other lines of research also show positive effects of using social norms [44] and commitments [45] to encourage consumers to behave more sustainably. Future research directly comparing the effectiveness of these other factors in addition to attitudes might provide more information about how to encourage consumers to purchase bio-based and other more sustainable products.

Another limitation was the potential disconnect between willingness to pay for a plastic bottle compared to the objective behaviour measure of donation. Participants might not have seen a direct connection between paying more for a water bottle and donating to plant trees, as reflected in the small correlation between them. Future research should investigate actual consumer behaviour and test whether participants would actually pay as much for a bio-based product as they indicated. The remote nature of the objective 
behaviour measure might also be the reason why we did not find an effect of attitude on donation behaviour, as the attitude questions were specifically about the different types of plastic.

Another potential limitation of this research is the use of single or two-item measures to assess most of the factors investigated in this research. Given the pioneering nature of this research, we chose many measures based on their simplicity and face value, aiming to get a first indication of participants' perceptions of (bio-based) plastics. While we replicated many of the measures in multiple studies (i.e., attitudes, willingness to pay, perceived importance to recycle), we are aware that the use of single and two-item measures makes it impossible to gauge the statistical validity and reliability of these measures. We therefore urge caution when interpreting the results and emphasise the need to independently replicate the findings using validated multi-item scales.

The data for the current research were collected from Western participants residing in multiple countries. This sample was chosen to get a first and general insight into consumer (bio-based) plastic perceptions. However, the wide spread of the sample also means that the results might not generalise to consumer perceptions in specific countries.

\section{General Conclusions}

Plastic production and disposal are an often-overlooked contributor to climate change. While consumers are increasingly becoming aware of plastic's negative effects on marine life, many remain unaware of the large amounts of $\mathrm{CO}_{2}$ that are released during the production and lifecycle of plastic products. One possible solution to this plastic problem is the market introduction of more sustainable products (e.g., bio-based plastics). This transition requires that (1) companies provide these environmentally friendly products and that (2) consumers accept and are willing to purchase them. Across four studies, we showed that consumers are very positive towards bio-based plastics and are willing to pay a price premium for them. However, we also demonstrated that many consumers lack knowledge about the properties of these new plastics and harbour misconceptions, particularly by overestimating biodegradability. We also showed that these misconceptions can be resolved through brief written messages. After being informed about bio-based plastics' properties and benefits, consumers attitudes towards products made of bio-based plastic remain positive and they are still willing to pay a price premium. These are encouraging results with regard to a transition towards sustainability, and the results contribute to the broader literature identifying psychological predictors of pro-environmental behaviour, including emotions, values, norms, and beliefs [26,43-45].

Supplementary Materials: The following are available online at https://osf.io/p3ftu. The supplementary materials include additional information about the subject pool and potential skewness of the data, non-parametric analyses, descriptive texts describing (bio-based) plastic as seen by the participants, and additional analyses that did not make it into the final version of the paper.

Author Contributions: Conceptualization, M.V.Z. and F.v.H.; methodology, M.V.Z. and F.v.H.; software, M.V.Z.; validation, M.V.Z., F.v.H. and C.B.; formal analysis, M.V.Z.; investigation, M.V.Z.; data curation, M.V.Z.; writing—original draft preparation, M.V.Z.; writing—review and editing, M.V.Z., F.v.H., C.B. and G.-J.M.G.; visualization, M.V.Z.; supervision, F.v.H. and C.B.; project administration, M.V.Z. and F.v.H.; funding acquisition, G.-J.M.G. All authors have read and agreed to the published version of the manuscript.

Funding: This research was funded by Netherlands Organisation for Scientific Research (NWO) (grant number 731.017.203) in the framework of the Innovation Fund for Chemistry and from the Ministry of Economic Affairs in the framework of the "TKI/PPS-Toeslagregeling". The authors thank LEGO SYSTEM A/S and Avantium for co-funding this project. The APC was funded by the University of Amsterdam.

Institutional Review Board Statement: All studies were conducted according to the guidelines of the Declaration of Helsinki, and approved by the Institutional Review Board (or Ethics Committee) of University of Amsterdam (Study 1: protocol code 2019-SP-11418 approval date 31-10-2019; Study 2: 
protocol code 2018-SP-9675 approval date 26-09-2019; Study 3: protocol code 2018-SP-9710 approval date 26-09-2019; Study 4: protocol code 2020-SP-11643, approval date 20-01-2020).

Informed Consent Statement: Informed consent was obtained from all subjects involved in the study.

Data Availability Statement: The data and syntax for all studies can be found on OSF: https: / / osf.io/p3ftu.

Conflicts of Interest: The authors declare no conflict of interest. The funders had no role in the design of the study; in the collection, analyses, or interpretation of data; in the writing of the manuscript, or in the decision to publish the results.

\section{References}

1. PlasticsEurope. Plastic-The Facts 2019: An analysis of European Plastics Production, Demand and Waste Data; PlaticsEurope: Brussels, Belgium, 2019.

2. Hamilton, L.A.; Feit, S. Plastic E Climate: The Hidden Costs of a Plastic Planet; Kristler, A., Muffett, C., Eds.; CIEL: Washington, DC, USA, 2019.

3. RESTCo. Media Coverage of Plastic Pollution. Available online: https://www.restco.ca/Plastic_Pollution_Media_Coverage. shtml (accessed on 20 July 2020).

4. Heidbreder, L.M.; Bablok, I.; Drews, S.; Menzel, C. Tackling the plastic problem: A review on perceptions, behaviors, and interventions. Sci. Total Environ. 2019, 668, 1077-1093. [CrossRef]

5. Herbes, C.; Beuthner, C.; Ramme, I. Consumer attitudes towards biobased packaging-A cross-cultural comparative study. J. Clean. Prod. 2018, 194, 203-218. [CrossRef]

6. European Bioplastics. Bioplastics Market Data. Available online: https://www.european-bioplastics.org/market/ (accessed on 17 December 2019).

7. Bourguignon, D. Plastics in a Circular Economy: Opportunities and Challenges; European Parliamentary Research Service: Brussels, Belgium, 2017.

8. Ellen McArthur Foundation. The New Plastic Economy: Rethinking the Future of Plastics E Catalysing Action in the New Plastics Economy; GAM Digital: Barcelona, Spain, 2016.

9. PAI Partners. ESG Lab | The Plastics Issue. Available online: https://www.paipartners.com/mediaitem/the-plastics-issue/ (accessed on 11 January 2021).

10. Crippa, M.; Guizzardi, D.; Muntean, M.; Schaaf, E.; Solazzo, E.; Monforti-Ferrario, F.; Olivier, J.; Vignati, E. Fossil CO 2 Emissions of All World Countries-2020 Report; EU Emissions Database for Global Atmospheric Research (EDGAR): Luxembourg, Luxembourg, 2020.

11. Murcia Valderrama, M.A.; van Putten, R.-J.; Gruter, G.-J.M. The potential of oxalic-And glycolic acid based polyesters (review). Towards $\mathrm{CO}_{2}$ as a feedstock (Carbon Capture and Utilization-CCU). Eur. Polym. J. 2019, 119, 445-468.

12. Ritchie, H.; Our World in Data. Plastic Pollution. Available online: https:/ / ourworldindata.org/plastic-pollution (accessed on 6 November 2020).

13. van den Oever, M.; Molenveld, K.; van der Zee, M.; Bos, H. Bio-Based and Biodegradable Plastics-Facts and Figures: Focus on Food Packaging in the Netherlands; Wageningen Food \& Biobased Research: Wageningen, The Netherlands, 2017.

14. Klein, F.; Emberg, A.; Menrad, K.; Möhring, W.; Blesin, J.-M. Influencing factors for the purchase intention of consumers choosing bioplastic products in Germany. Sustain. Prod. Consum. 2019, 19, 33-43. [CrossRef]

15. Eerhart, A.J.J.E.; Faaij, A.P.C.; Patel, M.K. Replacing fossil based PET with biobased PEF; process analysis, energy and GHG balance. Energy Environ. Sci. 2012, 5, 6407-6422. [CrossRef]

16. Orset, C.; Barret, N.; Lemaire, A. How consumers of plastic water bottles are responding to environmental policies? Waste Manag. 2017, 61, 13-27. [CrossRef] [PubMed]

17. Kainz, U.; Zapilko, M.; Decker, T.; Menrad, K. Consumer-relevant information about bioplastics. In First International Conference on Resource Efficiency in Interorganizational Networks-ResEff 2013, Proceedings of the First International Conference on Resource Efficiency in Interorganizational Networks, Göttingen, Germany, 13-14 November 2013; Geldermann, J., Schumann, M., Eds.; Universitätsverlag Göttingen: Göttingen, Germany, 2013; pp. 391-402.

18. Koutsimanis, G.; Getter, K.; Behe, B.; Harte, J.; Almenar, E. Influences of packaging attributes on consumer purchase decisions for fresh produce. Appetite 2012, 59, 270-280. [CrossRef] [PubMed]

19. Lynch, D.H.; Klaassen, P.; Broerse, J.E. Unraveling Dutch citizens' perceptions on the bio-based economy: The case of bioplastics, bio-jetfuels and small-scale bio-refineries. Ind. Crop. Prod. 2017, 106, 130-137. [CrossRef]

20. Dilkes-Hoffman, L.; Ashworth, P.; Laycock, B.; Pratt, S.; Lant, P. Public attitudes towards bioplastics-Knowledge, perception and end-of-life management. Resour. Conserv. Recycl. 2019, 151, 104479. [CrossRef]

21. InnProBio, Biodegradability: Exposing Some of the Myths and Facts. 2017. Available online: https://www.biobasedconsultancy. com/uploads/files/InnProBio_Factsheet_n3.pdf (accessed on 10 January 2021).

22. Blesin, J.-M.; Jaspersen, M.; Möhring, W. Boosting plastics' image? Communicative challenges of innovative bioplastics. J. Hist. Polym. Mater. Plast. Herit. Hist. 2017, 3, 1-5. 
23. Ajzen, I.; Fishbein, M. The Influence of Attitudes on Behavior. In The Handbook of Attitudes; Albarracín, D., Johnson, B.T., Zanna, M.P., Eds.; Erlbaum: Mahwah, NJ, USA, 2005; pp. 173-221.

24. Koenig-Lewis, N.; Palmer, A.; Dermody, J.; Urbye, A. Consumers' evaluations of ecological packaging-Rational and emotional approaches. J. Environ. Psychol. 2014, 37, 94-105. [CrossRef]

25. Sijtsema, S.J.; Onwezen, M.C.; Reinders, M.J.; Dagevos, H.; Partanen, A.; Meeusen, M. Consumer perception of bio-based products-An exploratory study in 5 European countries. J. Life Sci. 2016, 77, 61-69. [CrossRef]

26. Zwicker, M.V.; Nohlen, H.U.; Dalege, J.; Gruter, G.-J.M.; van Harreveld, F. Applying an attitude network approach to consumer behaviour towards plastic. J. Environ. Psychol. 2020, 69, 101433. [CrossRef]

27. Palan, S.; Schitter, C. Prolific.ac-A subject pool for online experiments. J. Behav. Exp. Financ. 2018, 17, 22-27. [CrossRef]

28. Champely, S.; Ekstrom, C.; Dalgaard, P.; Gill, J.; Weibelzahl, S.; Anandklumar, A.; Ford, C.; Volcic, R.; de Rosario, H. Basic Functions for Power Analysis; R Core Team: Vienna, Austria, 2020.

29. Thompson, M.M.; Zanna, M.P.; Griffin, D.W. Let's not be indifferent about (attitudinal) ambivalence. In Attitude Strength: Antecedents and Consequences; Lawrence Erlbaum Associates, Inc.: Hillsdale, NJ, USA, 1995; pp. 361-386.

30. van Harreveld, F.; Nohlen, H.U.; Schneider, I.K. The ABC of ambivalence: Affective, behavioral, and cognitive consequences of attitudinal conflict. In Advances in Experimental Social Psychology; Elsevier: Amsterdam, The Netherlands, 2015; pp. 285-324.

31. Kaplan, K.J. On the ambivalence-indifference problem in attitude theory and measurement: A suggested modification of the semantic differential technique. Psychol. Bull. 1972, 77, 361-372. [CrossRef]

32. Itzchakov, G.; Van Harreveld, F. Feeling torn and fearing rue: Attitude ambivalence and anticipated regret as antecedents of biased information seeking. J. Exp. Soc. Psychol. 2018, 75, 19-26. [CrossRef]

33. Taufik, D.; Reinders, M.J.; Molenveld, K.; Onwezen, M.C. The paradox between the environmental appeal of bio-based plastic packaging for consumers and their disposal behaviour. Sci. Total Environ. 2020, 705, 135820. [CrossRef]

34. Haider, T.P.; Völker, C.; Kramm, J.; Landfester, K.; Wurm, F.R. Plastics of the future? The impact of biodegradable polymers on the environment and on society. Angew. Chem. Int. Ed. 2019, 58, 50-62. [CrossRef]

35. European Bioplastics. Biobased Plastics-Fostering A Resource Efficient Circular Economy: Benefits, Feedstock Types, Sustainable Sourcing, Land Use; European Bioplastics: Berlin, Germany, 2020.

36. Lovett, J.; de Bie, F. Sustainable Sourcing of Feedstocks for Bioplastics: Clarifying Sustainability Aspects around Feedstock Use for the Production of Bioplastics; Corbion Group: Amsterdam, The Netherlands, 2016.

37. Bioplastics NEWS. Available online: https://bioplasticsnews.com/2018/09/12/bioplastic-feedstock-1st-2nd-and-3rdgenerations / (accessed on 22 March 2021).

38. Carrington, M.J.; Neville, B.; Whitwell, G. Why ethical consumers don't walk their talk: Towards a framework for understanding the gap between the ethical purchase intentions and actual buying behaviour of ethically minded consumers. J. Bus. Ethics 2010, 97, 139-158. [CrossRef]

39. Bulmer, S. Principles of Statistics; Dover Publications: New York, NY, USA, 1979.

40. IEA. World Energy Outlook 2014; IEA, Ed.; IEA: Paris, France, 2014.

41. Confente, I.; Scarpi, D.; Russo, I. Marketing a new generation of bio-plastics products for a circular economy: The role of green self-identity, self-congruity, and perceived value. J. Bus. Res. 2020, 112, 431-439. [CrossRef]

42. Sheeran, P. Intention-Behavior relations: A conceptual and empirical review. Eur. Rev. Soc. Psychol. 2002, 12, 1-36. [CrossRef]

43. Bissing-Olson, M.J.; Fielding, K.; Iyer, A. Experiences of pride, not guilt, predict pro-environmental behavior when proenvironmental descriptive norms are more positive. J. Environ. Psychol. 2016, 45, 145-153. [CrossRef]

44. Poškus, M.S. Using social norms to encourage sustainable behaviour: A meta-analysis. Psychology 2016, 53, 44-58.

45. Jaeger, C.M.; Schultz, P.W. Coupling social norms and commitments: Testing the underdetected nature of social influence. J. Environ. Psychol. 2017, 51, 199-208. [CrossRef] 